\title{
Doxycycline Ameliorates Schizophrenia-Like Behaviors in Experimental Models in Mice by Targeting Underlying Oxidative Stress
}

\section{Benneth Ben-Azu1, Itivere Adrian Omogbiya1,2*, Adegbuyi Oladele Aderibigbe1, Solomon Umukoro1, Abayomi Mayowa Ajayi ${ }^{1}$, Aya-Ebi Okubo Eneni' ${ }^{1}$, Ezekiel O. Iwalewa ${ }^{1}$}

\author{
${ }^{1}$ Department of Pharmacology and Therapeutics, College of Medicine, University of Ibadan, Ibadan, Nigeria \\ ${ }^{2}$ Department of Pharmacology and Therapeutics, Faculty of Basic Medical Sciences, Delta State University, Abraka, Nigeria \\ Email: *omogbiyaitivere@yahoo.com
}

How to cite this paper: Ben-Azu, B., Omogbiya, I.A., Aderibigbe, A.O., Umukoro, S., Ajayi, A.M., Eneni, A.-E.O. and Iwalewa, E.O. (2016) Doxycycline Ameliorates Schizophrenia-Like Behaviors in Experimental Models in Mice by Targeting Underlying Oxidative Stress. Journal of Behavioral and Brain Science, 6, 539-562. http://dx.doi.org/10.4236/jbbs.2016.613048

Received: October 16, 2016

Accepted: December 10, 2016

Published: December 13, 2016

Copyright $\odot 2016$ by authors and Scientific Research Publishing Inc. This work is licensed under the Creative Commons Attribution International License (CC BY 4.0).

http://creativecommons.org/licenses/by/4.0/

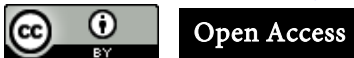

\begin{abstract}
Current evidences support the inhibition of oxidative and inflammatory signaling mechanisms in the treatment of schizophrenia; as cure for this disease still remains limited. Doxycycline is a tetracycline antibiotic (a minocycline congener) with strong antioxidant and anti-inflammatory properties, and better pharmacokinetic profiles. Preclinical evidence indicates that minocycline possesses antipsychotic properties. This present study was designed to evaluate the effect of doxycycline on schizophrenialike behaviors, as well as biomarkers of oxidative stress in mice brains. Noveltyinduced rearing (NIR) behavior was used to evaluate the tranquilizing effect of doxycycline $(25-200 \mathrm{mg} / \mathrm{kg})$. The acute antipsychotic effects of doxycycline were assessed using apomorphine-induced stereotypy, ketamine-induced stereotypy, hyperlocomotion and enhanced immobility in forced swim test (FST). Catalepsy test was also employed to evaluate the extrapyramidal adverse effect of doxycycline in mice. The chronic antipsychotic effect of doxycycline was evaluated following oral administration of doxycycline in combination with ketamine $(100 \mathrm{mg} / \mathrm{kg})$ intraperitoneally for 10 days. Twenty four hours after the last administration, positive (locomotor activity), cognitive (Y-maze) and negative (FST) symptoms were assessed. Thereafter, levels of biomarkers of oxidative stress were evaluated in mice brains. Doxycycline significantly $(P<0.05)$ decreased NIR, inhibited stereotypy induced by apomorphine and ketamine. Additionally, doxycycline significantly $(P<0.05)$ prevented ketamineinduced hyperlocomotion, cognitive deficit and reduced enhanced-immobility by ketamine in mice. Furthermore, doxycycline decreased malondialdehyde concentrations in a dose-related manner. Moreover, doxycycline significantly $(P<0.05)$ prevented the decrease in glutathione, and increased activities of superoxide dismutase and catalase in brain tissues. The results from this study suggest that doxycycline
\end{abstract}


ameliorated schizophrenic-like behaviors via mechanisms related to attenuation of oxidative stress in mouse brain.

\section{Keywords}

Schizophrenia, Antipsychotics, Oxidative Stress, Antioxidant, Doxycycline

\section{Introduction}

Psychosis (e.g., Schizophrenia) is a heterogeneous neuropsychiatric disorder characterized by distorted or non-existent sense of reality [1]. It affects about $1 \%$ of the world's population [2]. Schizophrenia is characterized by positive (e.g., hallucinations), negative (e.g., social isolation) and cognitive (e.g., executive and memory dysfunction) symptoms [3]. While the positive symptoms results from hyperdopaminergic activity in the mesolimbic pathways, the negative and cognitive deficits emanate from hypodopaminergic system of the prefrontal cortex [4].

Although first-generation antipsychotics are responsive in reducing the positive symptoms, these agents have been relatively less effective in ameliorating the severity of negative and cognitive deficits, and are also limited by their high tendency to produce extrapyramidal side effects, due to excessive blockade of dopaminergic $\mathrm{D}_{2}$ receptors [5]. In contrast, the second-generation antipsychotics are effective in ameliorating all groups of symptoms with lesser extra-pyramidal side effects, but in turn hold greater risk of cardiovascular diseases, diabetes, agranulocytosis etc. [6]. Moreover, regular intake of these agents may also increase oxidative stress and further enhance the progression of the disease [7]. Notably, Pazvantoglu et al. [8] demonstrated that the severity of the symptoms depended on the total antioxidant levels. The brain has been reported to be more vulnerable to oxidative stress, because it is the most metabolically active tissue in the body and so generates a high load of reactive oxygen moieties, which triggers lipid peroxidation that leads to several behavioral perturbations [7]. Hence, the need for newer antipsychotic agents with multipronged mechanisms of action that could target various aspects of the pathologies of schizophrenia has become imperative [7] [8]. To this end, the second-generation tetracycline antibiotic drugs (e.g., minocycline, doxycycline) have recently been attracting much attention in neuropsychiatric preclinical researches due to their antioxidant and anti-inflammatory/immunomodulatory mechanisms of action [9].

Doxycycline is a long acting second-generation tetracycline antibiotic which is rapidly absorbed and penetrates well into the brain, with very low toxicity profile [10]. Globally, doxycycline has remained one of the most commonly used inexpensive broadspectrum antibiotics and is included in the list of Essential Medicine of the World Health Organization (WHO) [10]. Similar to minocycline, doxycycline possesses strong neuroprotective effect and this is closely attributed to its anti-inflammatory, antioxidant, anti-apoptotic and neurotrophic properties [9] [11] [12]. 
During the last decade, the neurotherapeutic potentials of minocycline and doxycycline in the treatment of mental disorders have reasonably increased [7] [12] [13]. However, there is a lack of preclinical studies investigating the psychotropic effects of doxycycline as a therapeutic agent for schizophrenia. Indeed, recent findings from preclinical studies suggest possible beneficial effects of minocycline as adjunctive therapy for the treatment of negative and cognitive symptoms of schizophrenia [13] [14]. In this context, the therapeutic properties of doxycycline relative to that of minocycline, suggests that it may also have clinical application in schizophrenia symptomology, most especially against the negative and cognitive symptoms of the disease [15] [16]. Therefore, this study was designed to evaluate the antipsychotic property of doxycycline by specifically investigating its effects on: 1) positive schizophrenia-like behavior, 2) negative schizophrenia-like behavior, 3) cognitive schizophrenia-like behavior and 4) biomarkers of oxidative stress in mouse brain.

\section{Materials and Methods}

\subsection{Experimental Animals}

Male Swiss mice (20 - 25 g; 6 weeks old) were obtained from the Central Animal House, Delta State University, Abraka. The animals were housed five per plastic cage $(42 \times 30 \times$ $27 \mathrm{~cm})$ at room temperature $\left(25^{\circ} \mathrm{C} \pm 1^{\circ} \mathrm{C}\right)$ with a $12: 12 \mathrm{hr}$ light/dark cycle. They were fed with standard rodent pellet food and water ad libitum throughout the experimental period. They were acclimatized for at least 1 week prior to commencement of the experiments. The experiments were performed according to the National institutes of Health Guide for Care and Use of Laboratory Animals (Publication No. 85 - 23, revised 1985). Also, efforts were made to minimize the suffering of the animals by careful handling, treatments and euthanization of the animals.

\subsection{Drugs and Chemicals}

Doxycycline (DOX) (Hovid Pharmaceutical industry, Malaysia), apomorphine (APO) (Sigma-Aldrich, St. Louis, USA), ketamine (KET) hydrochloride (Sigma-Aldrich, St. Louis, USA), haloperidol (HLP) (Sigma-Aldrich, St. Louis, USA), risperidone (RIS) (SigmaAldrich, St. Louis, USA), trichloroacetic acid (TCA) (Burgoyne Burbidges \& Co., Mumbai, India), thiobarbituric acid (TBA) (Guanghua Chemical Factory Co. Ltd., China), Ellman Reagent [5',5'-Dithiobis-(2-nitrobenzoate) DTNB] (Sigma-Aldrich, St. Louis, MO, USA), hydrogen peroxide $\left(\mathrm{H}_{2} \mathrm{O}_{2}\right)$ (BDH Chemicals Ltd., Poole, England) and adrenaline (Sigma-Aldrich, St. Louis, USA) were used in the study.

\subsection{Drug Preparation}

Doxycycline, risperidone and haloperidol were dissolved in distilled water immediately before use and administered per oral (p.o.). Apomorphine was also dissolved in distilled water immediately before use and administered intraperitoneally (i.p.). Ketamine was diluted with distilled water and administered (i.p.). The doses of Doxycycline used in this study were selected based on the results from preliminary investigations. Halo- 
peridol was used as the positive control for apomorphine model, while risperidone was used as the positive control for ketamine models, since ketamine-induced model of schizophrenia has been demonstrated to be more responsive to atypical antipsychotic [17]. Appropriate vehicle (VEH)-controlled groups were also assessed simultaneously per oral with $10 \mathrm{~mL} / \mathrm{kg}$ of distilled water.

\subsection{Experimental Design}

For acute studies, novelty-induced rearing (NIR) behavior was employed. Single dose of apomorphine (1 mg/kg, i.p.) [18] administration was used to induced stereotypy behavior. Different doses of ketamine were used in this study: Single dose of ketamine (10 $\mathrm{mg} / \mathrm{kg}$, i.p.) [17] administrations was used to induce stereotypy and hyperlocomotion (positive symptoms) respectively; ketamine (30 mg/kg, i.p./day) [19] was used for enhancement of immobility time (negative symptoms) following 5 days treatment and thereafter animals were treated with single administration of doxycycline $24 \mathrm{hr}$ after the last treatment with ketamine, followed by behavioral despair assessment in the forced swim test. Furthermore, catalepsy test was also employed for the assessment of cataleptic behavior (extrapyramidal side effect) (Figure 1).

For sub-chronic study, repeated ketamine (100 mg/kg, i.p./day) [20] for 10 days was used to induced schizophrenia-like behaviors and oxidative alteration in mice brains. Mice were pretreated with either vehicle $(10 \mathrm{~mL} / \mathrm{kg}$, p.o.), standard antipsychotic agents (risperidone, $0.5 \mathrm{mg} / \mathrm{kg}$, p.o.) or doxycycline (25, 50, 100 and $200 \mathrm{mg} / \mathrm{kg}$, p.o.) $1 \mathrm{hr}$ prior to the administration of ketamine (100 mg/kg, i.p.) for 10 days. Animals were evaluated for behavioral phenotypes $24 \mathrm{hr}$ after the last administration of doxycycline and ketamine respectively, on days 9, 10 and 11:1) hyperlocomotor activity (open field test) (representing positive symptoms) on the $9^{\text {th }}$ day, 2) Y-maze test (representing

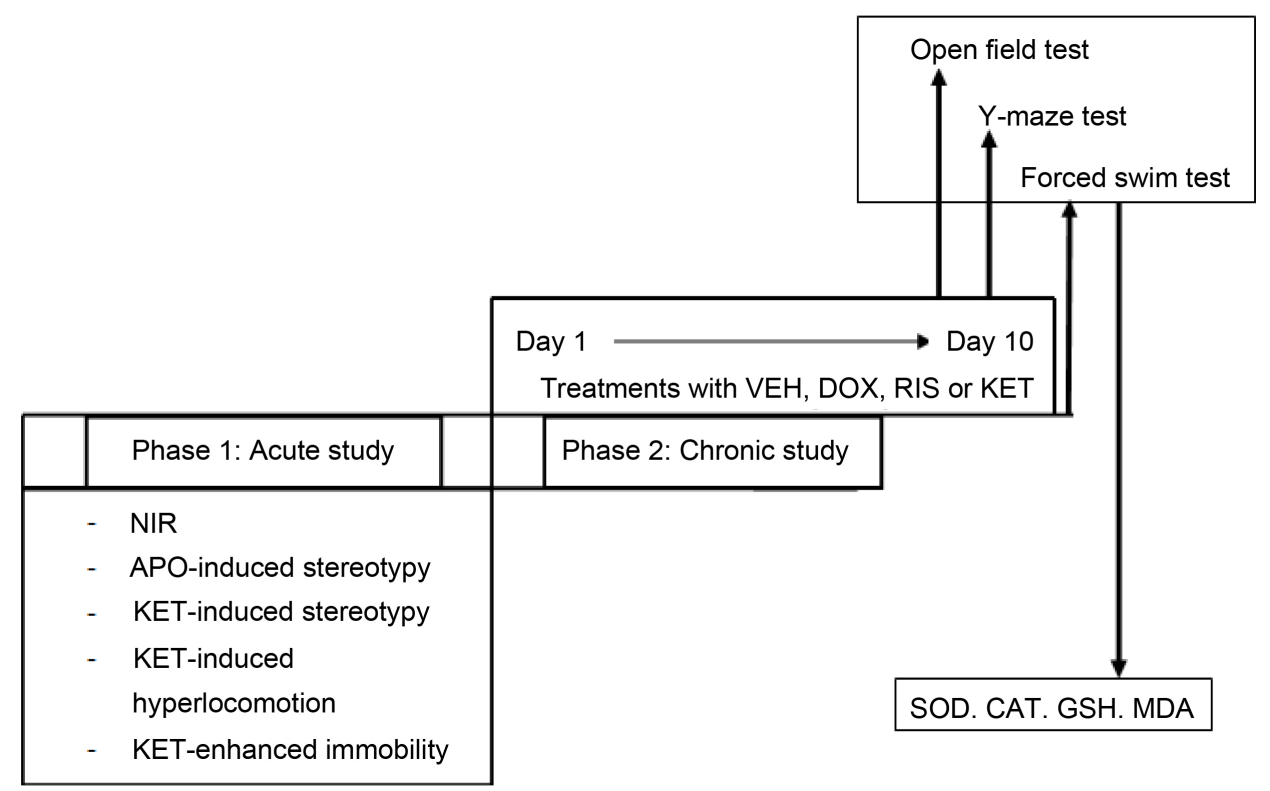

Figure 1. Experimental protocol. 
cognitive symptoms) on the $10^{\text {th }}$ day and 3 ) forced swim test (representing negative symptoms) was carried out $24 \mathrm{hr}$ after the last administration (on the $11^{\text {th }}$ day). Immediately after the behavioral tests, the animals were euthanized and the supernatant of the brain tissues were used to assay for levels of biomarkers of oxidative stress including superoxide dismutase (SOD), catalase (CAT), glutathione (GSH) and malondialdehyde (MDA) as presented in Figure 1.

\subsection{Acute Study}

\subsubsection{Assessment of Novelty-Induced Rearing (NIR) Behavior in Mice}

Novelty-induced rearing behavior was employed to evaluate the central excitatory/ inhibitory rearing behavior in mice [21]. The animals were divided into six treatment groups $(\mathrm{n}=5)$. The group 1 received vehicle (distilled water) $(10 \mathrm{~mL} / \mathrm{kg}$, p.o.), groups 2 - 5 were treated with $\operatorname{DOX}\left(25,50,100\right.$ and $200 \mathrm{mg} / \mathrm{kg}$, p.o.), while the $6^{\text {th }}$ group received RIS ( $0.5 \mathrm{mg} / \mathrm{kg}$, p.o.), respectively. One hour later, mice were individually placed in a transparent Plexiglas chamber $(45 \mathrm{~cm} \times 25 \mathrm{~cm} \times 25 \mathrm{~cm})$ and the rearing frequencies (number of times the animal stood on its hind limbs or with its fore limbs against the walls of the observation box or free in the air) were recorded for $5 \mathrm{~min}$. The arena was cleaned with $70 \%$ ethanol to eliminate olfactory bias (residual odour) after each session [17].

\subsubsection{Apomorphine-Induced Stereotypy}

The antipsychotic effect of DOX was assessed using the Apomorphine-induced stereotyped behavior as previously described by Bourin et al. [18]. The mice were randomly divided into six treatment groups $(\mathrm{n}=5)$. Group 1 received vehicle $(10 \mathrm{~mL} / \mathrm{kg}, \mathrm{p} . \mathrm{o}$.) (serving as negative control), while groups 2 - 5 were pretreated with $\operatorname{DOX}(25,50,100$ and $200 \mathrm{mg} / \mathrm{kg}$, p.o.) and the $6^{\text {th }}$ group was pretreated with HLP $(1 \mathrm{mg} / \mathrm{kg}$, p.o.) as positive control. Sixty minutes later, each animal in groups 1 - 6 received i.p. injection of APO $(1 \mathrm{mg} / \mathrm{kg})$ and mouse was placed immediately in a transparent observation chamber $(20 \mathrm{~cm} \times 20 \mathrm{~cm} \times 23 \mathrm{~cm})$. Thereafter, stereotype behaviors were observed for $2 \mathrm{~min}$ at $10,15,30,45$ and $60 \mathrm{~min}$ after APO injection. Stereotype behaviors were scored as: $0=$ absence of stereotype behavior; 1 = presence of stereotype movements of the head; $2=$ intermittent sniffing; 3 = chewing; $4=$ intense licking. The observation chamber was cleaned with $70 \%$ ethanol after each test session [17].

\subsubsection{Ketamine-Induced Stereotypy}

Ketamine-induced psychosis was also employed to screen for the antipsychotic effect of DOX according to the method described by Ben-Azu et al. [17]. The mice were randomly divided into six treatment groups $(\mathrm{n}=5)$. Group 1 received vehicle $(10 \mathrm{~mL} / \mathrm{kg}$, p.o.) (Group 1 serving as negative control) while groups 2 - 5 were pretreated with $\operatorname{DOX}(25,50,100$ and $200 \mathrm{mg} / \mathrm{kg}, \mathrm{p} . \mathrm{o})$, and $6^{\text {th }}$ group was pretreated with RIS (0.5 $\mathrm{mg} / \mathrm{kg}$, p.o.) as positive control. Sixty minutes later, each animal in groups 1 - 6 received i.p. injection of sub-anaesthetic dose of KET $(10 \mathrm{mg} / \mathrm{kg})$ and mouse was placed immediately in a transparent observation chamber $(20 \mathrm{~cm} \times 20 \mathrm{~cm} \times 23 \mathrm{~cm})$ and ste- 
reotypy was observed for $2 \mathrm{~min}$ at 10,15, 20, 30 and $45 \mathrm{~min}$ respectively. Stereotyped behaviors were scored as described above. The observation chamber was also cleaned with $70 \%$ ethanol after each test session [17].

\subsubsection{Ketamine-Induced Hyperlocomotion}

Ketamine-induced hyperactivity was also used to screen for the antipsychotic effect of DOX as previously described by Ben-Azu et al. [17]. The mice were randomly divided into six treatment groups $(\mathrm{n}=5)$. Group 1 received vehicle $(10 \mathrm{~mL} / \mathrm{kg}$, p.o.), while groups 2 - 5 were pretreated with $\operatorname{DOX}\left(25,50,100\right.$ and $200 \mathrm{mg} / \mathrm{kg}$, p.o.) and the $6^{\text {th }}$ group was pretreated with RIS $(0.5 \mathrm{mg} / \mathrm{kg}$, p.o.) as positive control. Sixty minutes thereafter, groups 1 - 6 received i.p. injection of sub-anaesthetic dose of KET (10 mg/kg). Thereafter, the animals were individually placed at the center of an open field chamber $(35 \times 30 \times 23 \mathrm{~cm})$. The duration of ambulation and number of line crossed were recorded for $5 \mathrm{~min}$. The observation chamber was also cleaned with $70 \%$ ethanol as earlier described [17].

\subsubsection{Ketamine-Enhanced Immobility in Forced Swim Test}

The antipsychotic effect of DOX was also screened using ketamine-enhanced immobility in forced swim test that is predictive of the negative symptoms of schizophrenia; which is reflected as a state of despair in mice as described by Chindo et al. [19] and Chatterjee et al. [20], with brief modifications. The reduction in the immobility time serves as a specific and selective index of antidepressant activity that can be used to alleviate the negative symptoms of schizophrenia. The mice were randomly divided into seven (7) treatment groups $(\mathrm{n}=5)$. Group 1 was pretreated with vehicle $(10 \mathrm{~mL} / \mathrm{kg}$, i.p.) once daily for 5 days while groups 2 - 6 were pretreated with a sub-anaesthetic dose of KET (30 mg/kg, i.p.) once daily for 5 days. After which, each mice were placed in a transparent glass cylinder (height $46 \mathrm{~cm}$, diameter $20 \mathrm{~cm}$ ) containing water at $25^{\circ} \mathrm{C}$ to a depth of $30 \mathrm{~cm}$ and was forced to swim for $5 \mathrm{~min}$ for habituation (pretest session) $1 \mathrm{~h}$ after the last treatment ( $5^{\text {th }}$ day) with ketamine. Twenty four hours after the last treatment ( $6^{\text {th }}$ day) with vehicle or KET respectively, group 2 received vehicular treatment $(10 \mathrm{~mL} / \mathrm{kg}$, p.o. $)$ as a negative control, groups 3 - 6 were treated with $\operatorname{DOX}(25,50,100$ and $200 \mathrm{mg} / \mathrm{kg}$, p.o), while group 7 was treated with RIS (0.5 mg/kg, p.o.) as positive control. Sixty minutes later, each animal was placed again in the water for 6 min and the immobility time was recorded for a period of 5 min with a stopwatch (test session) after discarding activity in the first $1 \mathrm{~min}$, during which the animal tries to escape. After each session, the mice were removed immediately from the cylinder, dried with a towel and kept in an open space until completely dried before returning the mice to their home cages.

\subsubsection{Catalepsy Test on DOX}

The cataleptic effect of the DOX was investigated according to the modified version previously described by Omogbiya et al. [21] and Chatterjee et al. [20]. The animals were divided into six treatment groups $(n=5)$. The group 1 was treated with vehicle 
(10 mL/kg, p.o.) while groups 2 - 5 were treated with DOX (25, 50, 100 and $200 \mathrm{mg} / \mathrm{kg}$, p.o) and the sixth group was treated with HLP (1 mg/kg, p.o.) $60 \mathrm{~min}$ before testing for catalepsy. The test was done by gently placing the fore limbs of each animal on an inclined horizontal plane wood surface $(\mathrm{H}=6 \mathrm{~cm} ; \mathrm{W}=4 \mathrm{~cm} ; \mathrm{L}=16 \mathrm{~cm})$ and the duration of akinesia (period of time the animal remained on an imposed posture, before initiating any active movement) in seconds was recorded.

\subsection{Sub-Chronic Study: Sub-Chronic Treatment of Ketamine-Induced Schizophrenia-Like Behavior and Oxidative Damage in Mouse Brain}

The model described by Chatterjee et al. [20] was adapted with little modification. Briefly, mice were divided into 7 groups $(n=5)$. Group 1 was pretreated with distilled water $(10 \mathrm{~mL} / \mathrm{kg}$, i.p.) as vehicle for 10 days, group 2 was treated with ketamine (100 $\mathrm{mg} / \mathrm{kg}$, i.p.) only for 10 days, while groups 3 - 6 were pretreated with $\operatorname{DOX}(25,50,100$ and $200 \mathrm{mg} / \mathrm{kg}$, p.o.) one hour prior to the administration of KET $(100 \mathrm{mg} / \mathrm{kg}$, i.p.) for 10 days, while group 7 received risperidone $(0.5 \mathrm{mg} / \mathrm{kg}$, p.o.) one hour prior to KET $(100 \mathrm{mg} / \mathrm{kg}$, i.p.) administration for 10 days.

\subsubsection{Behavioral Tests}

Behavioral tests were performed $24 \mathrm{hr}$ after the last administration of DOX and ketamine on days 9, 10 and 11, respectively. Each animal was evaluated for behavioral phenotypes as previously by Chatterjee et al. [20], i.e.: 1) hyperlocomotor activity (representing positive symptoms) on the $9^{\text {th }}$ day, 2) $\mathrm{Y}$-maze test (representing cognitive symptoms) on the $10^{\text {th }}$ day and 3 ) forced swim test (representing negative symptoms) was carried out $24 \mathrm{hr}$ after the last administration (on the $11^{\text {th }}$ day).

1) Open-field test (OFT)

Locomotor behavior was monitored using the open field test apparatus with brief modifications. The open field apparatus consisted of a wooden box measuring $35 \times 30 \times$ $23 \mathrm{~cm}$ with visible lines drawn to divide the floor into $36(20 \mathrm{~cm} \times 20 \mathrm{~cm})$ squares with a frontal glass wall, and placed in a sound free room. The animals were placed in the rear left square and left to explore it. The parameter measured includes number of lines crossed for 5 min using a stopwatch [21].

2) Y-maze test (YMT)

The effect of DOX on spontaneous alternation performance was also assessed using YMT which allows for the evaluation of cognitive searching behavior, as an index of spatial working memory dysfunction of schizophrenia. Animals were gently placed individually in the Y-maze apparatus, which consisted of three identical arms $(33 \times 11 \times$ $12 \mathrm{~cm}$ each) in which the arms were symmetrically separated at $120^{\circ}$. Each mouse was placed at the end of arm A and allowed to explore all the three arms (labeled A, B, C) freely for $5 \mathrm{~min}$, taking the following parameters: the number of arm visits and sequence (alternation) of arm visits visually. The percentage of alternations was calculated as total of alternations/(total arm entries-2). After each test session, the observation chamber was cleaned with $70 \%$ ethanol to remove residual odour [22]. 
3) Forced swim test (FST)

Briefly, each mouse was placed in a standardized transparent glass cylinder (Height $46 \mathrm{~cm}$, diameter $20 \mathrm{~cm}$ ) containing water at $25^{\circ} \mathrm{C}$ to a depth of $30 \mathrm{~cm}$ and was forced to swim for $5 \mathrm{~min}$ (pretest session) $1 \mathrm{hr}$ after the last treatment $\left(10^{\text {th }}\right.$ day) with ketamine for habituation. Twenty four hours after the pretest session (on the $11^{\text {th }}$ day), each animal was placed again in the same transparent Plexiglas cylinder containing water at $25^{\circ} \mathrm{C}$ to a depth of $30 \mathrm{~cm}$. They were then forced to swim for 6 min and the immobility time (which is the time the animal floats in the water in an upright position and made only slight movements to prevent sinking) was recorded for a period of 5 min with a stopwatch after discarding activity in the first $1 \mathrm{~min}$, during which the animal tries to escape. After each session, the mice were removed immediately from the cylinder, dried with a towel and kept in an open space until completely dried before returning them to their home cages [20].

\subsubsection{Biochemical Assays}

1) Preparation of brain tissues for biochemical assay

Immediately after the behavioral tests, the animals were decapitated under ether anaesthesia and the brains were immediately removed, weighed and kept in the refrigerator in the refrigerator with ice block for $30 \mathrm{~min}$. Thereafter, the whole brains were homogenized with $5 \mathrm{~mL}$ of $10 \% \mathrm{w} / \mathrm{v}$ phosphate buffer (0.1 M, PH 7.4). Each brain tissue homogenates were centrifuged at $10,000 \mathrm{~g}$ for $10 \mathrm{~min}$ at $4^{\circ} \mathrm{C}$, the pellet was discarded and the supernatant was immediately separated into various portions for the different biochemical assays.

2) Determination of superoxide dismutase (SOD) activity

The level of SOD activity was measured by the method described by Misra and Fridovich [23]. This method is based on the inhibition of superoxide dependent adrenaline auto-oxidation in a spectrophotometer adjusted at 480 nanometer $(\mathrm{nm})$. Brain supernatant of $1 \mathrm{~mL}$ was diluted in $9 \mathrm{~mL}$ of distilled water to make a 1 in 10 dilution. An aliquot of $0.2 \mathrm{~mL}$ of the diluted sample was added to $2.5 \mathrm{~mL}$ of $0.05 \mathrm{M}$ carbonate buffer $(\mathrm{pH}$ 10.2) to equilibrate in the spectrophotometer and the reaction was started by the addition of $0.3 \mathrm{~mL}$ of freshly prepared $0.3 \mathrm{mM}$ adrenaline to the mixture which was quickly mixed by inversion. The reference cuvette (Blank) contained $2.5 \mathrm{~mL}$ buffer, 0.3 $\mathrm{mL}$ of substrate (adrenaline) and $0.2 \mathrm{~mL}$ of distilled water. The increase in absorbance at $480 \mathrm{~nm}$ was monitored for $30 \mathrm{~s}$ for $150 \mathrm{~s}$. A unit of SOD activity was given as the amount of SOD necessary to cause 50\% inhibition of the oxidation of adrenaline [23].

3) Determination of catalase (CAT) activity

CAT activity was assayed by the method of Sinha [24], which was based on the disappearance of Hydrogen peroxide $\left(\mathrm{H}_{2} \mathrm{O}_{2}\right)$ in the presence of an enzyme source (catalase). Brain supernatant of the sample homogenate $(1 \mathrm{~mL})$ was mixed with $19 \mathrm{~mL}$ of distilled water to give a 1:20 dilution. Then, $1 \mathrm{~mL}$ of this was added to $5 \mathrm{~mL}$ of phosphate buffer ( $\mathrm{pH} 7.0)$ and $4 \mathrm{~mL}$ of $\mathrm{H}_{2} \mathrm{O}_{2}$ solution ( $800 \mu$ moles). The reaction mixture was mixed by a gentle swirling motion at room temperature. Then, $1 \mathrm{~mL}$ of this portion of the reaction mixture was withdrawn and added into $2 \mathrm{~mL}$ dichromate/acetic acid 
reagent. The absorbance was measured using spectrophotometer at $570 \mathrm{~nm}$ and change in absorbance at $60 \mathrm{~s}$ interval. The catalase activity was expressed as $\mu$ moles of $\mathrm{H}_{2} \mathrm{O}_{2}$ decomposed per minutes per mg protein.

4) Determination of glutathione (GSH) concentration

GSH concentration was assayed by the method described by Jollow et al. [25], which was based upon the development of a relatively stable (yellow) colour when 5', 5'-dithiobis-(2-nitrobenzoic acid) (DTNB) is added to sulfhydryl compounds. Brain homogenates of $0.4 \mathrm{~mL}$ was added to $0.4 \mathrm{~mL}$ of $20 \%$ trichloroacetic acid (TCA) and mixed by a gentle swirling motion and then centrifuged in a cold $\left(4^{\circ} \mathrm{C}\right)$ centrifuge at $10,000 \mathrm{rpm}$ for $20 \mathrm{~min}$. Then, $0.25 \mathrm{~mL}$ of the supernatant was added to $2 \mathrm{~mL}$ of $0.6 \mathrm{mM}$ DTNB and the final volume of the solution was made up to $3 \mathrm{~mL}$ with phosphate buffer $(0.2 \mathrm{M}, \mathrm{pH}$ 8.0). Absorbance was read at $412 \mathrm{~nm}$ against blank reagent-[ $2 \mathrm{~mL}$ of $0.6 \mathrm{mM} \mathrm{DTNB}+1$ $\mathrm{mL}$ phosphate buffer $(0.2 \mathrm{M}, \mathrm{pH} 8.0)$ ] using a spectrophotometer. The concentration of reduced GSH in the brain tissues was expressed as nanomoles per gram tissue (nmol/g tissue).

5) Estimation of brain level of malondialdehyde (MDA)

The brain level of MDA was measured according to the method described by Okhawa et al. [26]. This assay principle is based on the fact that lipid peroxidation generates unstable lipid peroxides that decompose to form a complex series of compounds including reactive carbonyl compounds. The polyunsaturated fatty acid peroxides produced generate MDA upon decomposition. MDA forms a 1:2 adduct with thiobarbituric acid (TBA) that gives rise to a pink color product when heated in acidic $\mathrm{pH}$, with a maximum absorbance of $532 \mathrm{~nm}$. In line with this, an aliquot of $0.4 \mathrm{~mL}$ of the sample was mixed with $1.6 \mathrm{~mL}$ of Tris-potassium chloride (Tris-KCl) buffer to which $0.5 \mathrm{~mL}$ of $30 \%$ trichloroacetic acid (TCA) was added. Then, $0.5 \mathrm{~mL}$ of $0.75 \%$ TBA was added and placed in a water bath for $45 \mathrm{~min}$ at $80^{\circ} \mathrm{C}$. This was then cooled in ice at $4^{\circ} \mathrm{C}$ and centrifuged at $3000 \mathrm{rpm}$ for $15 \mathrm{~min}$. The clear supernatant was collected and absorbance was measured against a reference blank of distilled water at $532 \mathrm{~nm}$. The MDA concentration was calculated using a Molar extinction coefficient of $1.56 \times 10^{5} \mathrm{M}^{-1} \mathrm{CM}^{-1}$ and the value was expressed as nanomole of MDA per gram tissue (nmol/g tissue).

6) Protein content estimation

This assay was done according to method described by Gornall et al. [27], using the Biuret method. $1 \mathrm{~mL}$ of the diluted sample was taken and added to $3 \mathrm{~mL}$ of Biuret reagent in triplicate. The mixture was incubated at room temperature for 30 min after which the absorbance was read at $540 \mathrm{~nm}$ using distilled water as blank. Bovine serum albumin $(1 \mathrm{mg} / \mathrm{mL})$ was used as standard and was measured in the range of $0.01-0.1$ $\mathrm{mg} / \mathrm{mL}[28]$.

\subsection{Statistical Analysis}

Statistical analysis was done using Graph Pad Prism software version 5.0 and data were expressed as Mean \pm S.E.M (standard error of mean). Following a normality test, data were analyzed using one-way analysis of variance (ANOVA) followed by post-hoc test 
(Newman-Keuls) for multiple comparisons where appropriate. A level of $P<0.05$ was considered as statistically significant for all tests.

\section{Results}

\subsection{Effect of DOX on Novelty-Induced Rearing (NIR) Behavior in Mice}

Pretreatment with DOX (50, 100 and $200 \mathrm{mg} / \mathrm{kg}$, p.o.) $[F(5,24)=79.76, P<0.0001]$ significantly $(P<0.05)$ reduced the NIR in a similar manner to RIS compared with the control; however, DOX $(25 \mathrm{mg} / \mathrm{kg}$, p.o.) showed no significant $(P>0.0 .5)$ reduction in NIR. Peak inhibition of NIR was observed at $200 \mathrm{mg} / \mathrm{kg}$ (Figure 2).

\subsection{Effect of DOX on Apomorphine-Induced Stereotypy}

In this study, apomorphine $(1 \mathrm{mg} / \mathrm{kg}$, i.p. $)$ administration significantly $(P<0.05)$ elicited marked stereotyped behaviors characterized by head movements, intermittent sniffing, chewing and intense licking, which are reflected in schizophrenic patient as a form of positive symptom (Figure 3). Pretreatment with DOX (100 and $200 \mathrm{mg} / \mathrm{kg}$, p.o.) significantly $(P<0.05)$ prevented apomorphine-induced stereotyped behaviors $[F$ $(5,24)=50.28, P<0.0001]$ (Figure 3). However, treatment with the lower doses of DOX (25 and $50 \mathrm{mg} / \mathrm{kg}$, p.o.) failed prevent this stereotypic behavior in the animals compared to APO-treated control group. Similar effects were also observed in animals treated with HLP $(1 \mathrm{mg} / \mathrm{kg}$, p.o. $)$, as it significantly $(P<0.05)$ prevented the manifestations of stereotyped behaviors induced by APO (Figure 3 ).

\subsection{Effect of Acute Administration of DOX on Ketamine-Induced Stereotypy}

Treatment with ketamine $(10 \mathrm{mg} / \mathrm{kg}$, i.p. $)$ demonstrated significant $(P<0.05)$ increase

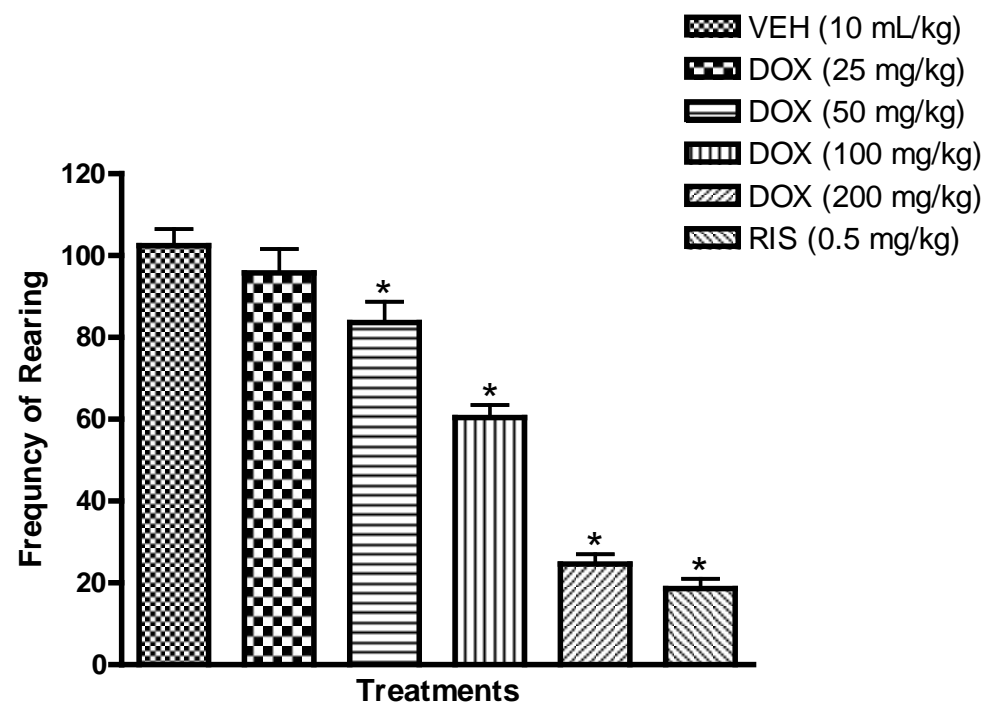

Figure 2. Effect of DOX on novelty-induced rearing behavior in mice. Values represent the mean of 5 animals/group. ${ }^{\star}$ Denotes $P<0.05$ compared with vehicle group. $\mathrm{VEH}=$ Vehicle DOX $=$ Doxycycline, $\mathrm{RIS}=$ Risperidone. 
in stereotyped behaviors compared to vehicle (Figure 4 ). The study showed that pretreatment with DOX (25 and $50 \mathrm{mg} / \mathrm{kg}$, p.o.) failed to demonstrate significant ( $P>$ $0.05)$ protection against ketamine induced stereotypic behavior whereas, treatment with higher doses of DOX (100 and $200 \mathrm{mg} / \mathrm{kg}$, p.o.) demonstrated significant $(P<0.05)$ protection against these stereotypic dispositions caused by ketamine in a similar manner to RIS $[F(5,24)=50.28, P<0.0001]$ (Figure 4).

\subsection{Effect of Acute Administration of DOX on Ketamine-Induced Hyperlocomotion}

The effect of DOX on ketamine-induced hyperlocomotion in mice, as assessed in the open-field test (OFT) is shown in Table 1 . The administration of ketamine $(10 \mathrm{mg} / \mathrm{kg}$, i.p.) induced hyperlocomotion compared to vehicular $(10 \mathrm{~mL} / \mathrm{kg})$ control group, as indexed by the increase in the number of line crossings and reduction in the duration

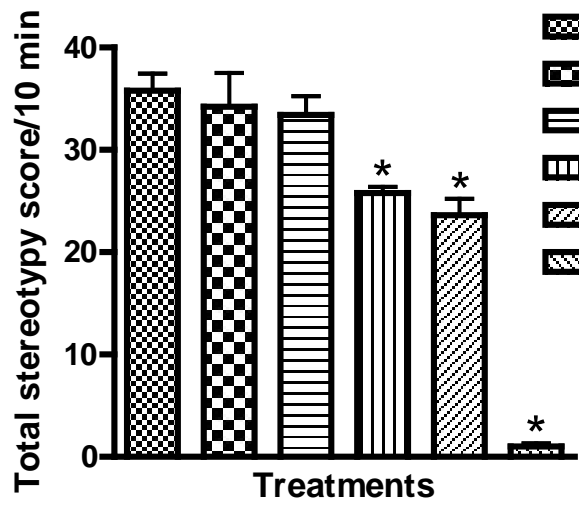

$\$ 0 \times 0$ Control (APO $1 \mathrm{mg} / \mathrm{kg})$

DOX (25 mg/kg) + APO

$\Longrightarrow D O X(50 \mathrm{mg} / \mathrm{kg})+\mathrm{APO}$

DOX (100 mg/kg) + APO

DOX $(200 \mathrm{mg} / \mathrm{kg})+A P O$

HLP (1 mg/kg) + APO

Figure 3. Effect of DOX on apomorphine-induced stereotypy. Value represents the mean \pm S.E.M of 5 animals/group. ${ }^{\star}$ Denotes $P<0.05$ compared with APO control group (ANOVA followed by Newman-Keuls test). APO = Apomorphine, DOX = Doxycycline, HLP = Haloperidol.

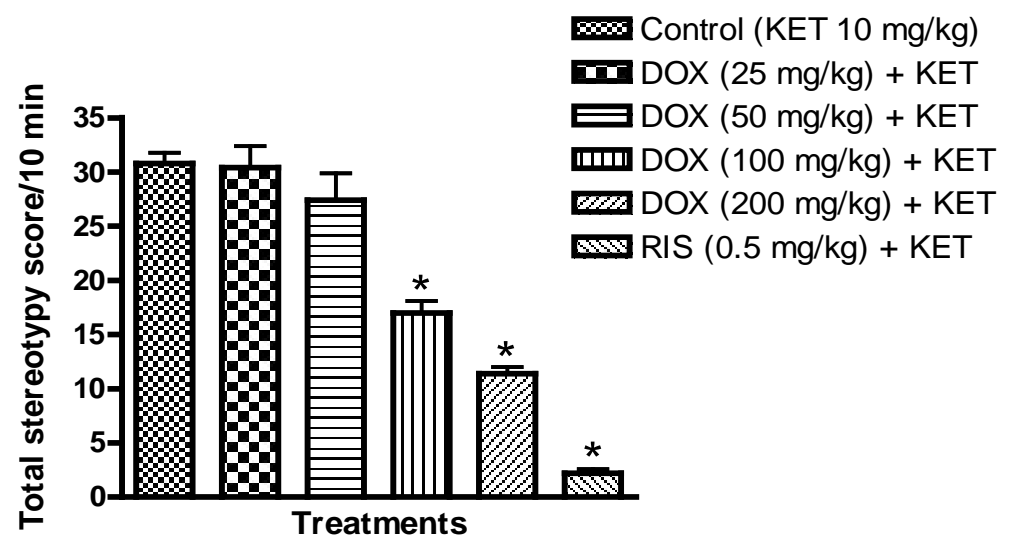

Figure 4. Effect of acute administration of DOX on ketamine-induced stereotypy. Value represents the mean \pm S.E.M of 5 animals/group. ${ }^{\star}$ Denotes $P<$ 0.05 compared with KET control group (ANOVA followed by Newman-Keuls test). $\mathrm{KET}=$ ketamine, $\mathrm{DOX}=$ Doxycycline, RIS $=$ Risperidone. 
Table 1. Effect of acute administration of DOX on ketamine-induced hyperlocomotion.

\begin{tabular}{cccc}
\hline Treatments & Dose $(\mathrm{mg} / \mathrm{kg})$ & Number of line crossing $(\mathrm{s})$ & Duration of ambulation \\
\hline KET & 10 & $129.0 \pm 4.77$ & $96.40 \pm 6.78$ \\
DOX & 25 & $125.0 \pm 3.53$ & $94.20 \pm 8.59$ \\
DOX & 50 & $123.6 \pm 2.08$ & $92.80 \pm 3.85$ \\
DOX & 100 & $105.6 \pm 2.59$ & $88.6 \pm 10.80$ \\
DOX & 200 & $90.40 \pm 4.14^{*}$ & $184.2 \pm 7.98^{\star}$ \\
RIS & 0.5 & $32.20 \pm 4.99^{*}$ & $223.6 \pm 9.33^{*}$ \\
\hline
\end{tabular}

Value represents the mean \pm SEM of 5 animals/group. ${ }^{*}$ Denotes $P<0.05$ compared with KET control group (ANOVA followed by Newman-Keuls test). KET $=$ ketamine, DOX $=$ Doxycycline, RIS $=$ Risperidone.

of ambulation in the OFT. DOX pretreatment $(200 \mathrm{mg} / \mathrm{kg}$, p.o. $)$ significantly $(P<0.05)$ prevented hyperlocomotion induced by ketamine $(10 \mathrm{mg} / \mathrm{kg}$, i.p. $)$ as indicated by the decrease in the number of line crossings $[F(6,28)=69.38, P<0.0001]$ and increase in duration of ambulation of the animals $[F(6,28)=42.58, P<0.0001]$ in the OFT similar to RIS compared to KET-treated group. However, treatments with lower doses of DOX (25, 50 and $100 \mathrm{mg} / \mathrm{kg}$, p.o.) did not show any significant protection against hyperlocomotion induced by ketamine in mice.

\subsection{Effect of Acute Administration of DOX on Ketamine-Enhanced Immobility in Forced Swim Test in Mice}

Effect of the acute (single dose of drug) administration of DOX and risperidone on ketamine-induced enhanced immobility in forced swim test is shown in Figure 5. Repeated ketamine administration $(30 \mathrm{mg} / \mathrm{kg}$, i.p./day) for 5 days significantly $(P<0.05)$ enhanced the duration of immobility in the forced swim test compared to the group treated with vehicle $(10 \mathrm{~mL} / \mathrm{kg}$, i.p.) in mice. However, single treatment with RIS (0.5 $\mathrm{mg} / \mathrm{kg}$, p.o.) significantly $(P<0.05)$ reduced enhancement in immobility time by ketamine. Meanwhile, acute treatment with DOX (50, 100 and $200 \mathrm{mg} / \mathrm{kg}$, p.o.) but not with $25 \mathrm{mg} / \mathrm{kg}$, p.o $24 \mathrm{hr}$ post-treatment with ketamine also showed significant $(P<$ $0.05)$ restoration against ketamine-induced immobility similar to RIS $[F(6,28)=25.47$, $P<0.0001$ ] compared to ketamine-treated group (Figure 5).

\subsection{Effect of DOX on Catalepsy Test}

The DOX (25 - $200 \mathrm{mg} / \mathrm{kg}$, p.o.) showed no significant $(P>0.05)$ prolongation in the duration of akinesia compared with the group that received vehicle $(10 \mathrm{~mL} / \mathrm{kg}$, p.o.). However, HLP $(1 \mathrm{mg} / \mathrm{kg}$, p.o.) significantly $(P<0.05)$ prolonged the duration of akinesia when compared to vehicle treated group (Figure 6).

\subsection{Prevention of Sub-Chronic Ketamine-Induced Hyperlocomotion, Alteration in Working Memory and Behavioral Despair by Doxycycline}

\subsubsection{Effect of DOX on Ketamine-Induced Hyperlocomotion}

Our data show that sub-chronic administration of ketamine $(100 \mathrm{mg} / \mathrm{kg}$, i.p./day) for 


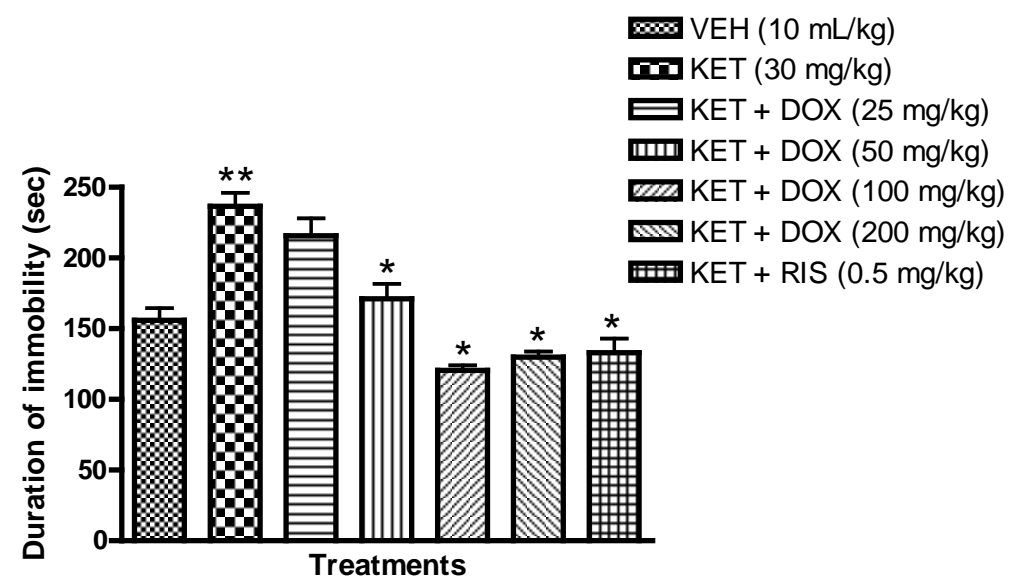

Figure 5. Effect of acute administration of DOX on ketamine-enhanced immobility in forced swim test in mice. Value represents the mean \pm S.E.M of 5 animals/group. ${ }^{\star \star}$ Denotes $P<0.05$ compared with vehicle control group, ${ }^{\star}$ Denotes $P<0.05$ compared with KET treated group (ANOVA followed by Newman-Keuls test). KET $=$ ketamine, DOX $=$ Doxycycline, RIS $=$ Risperidone.

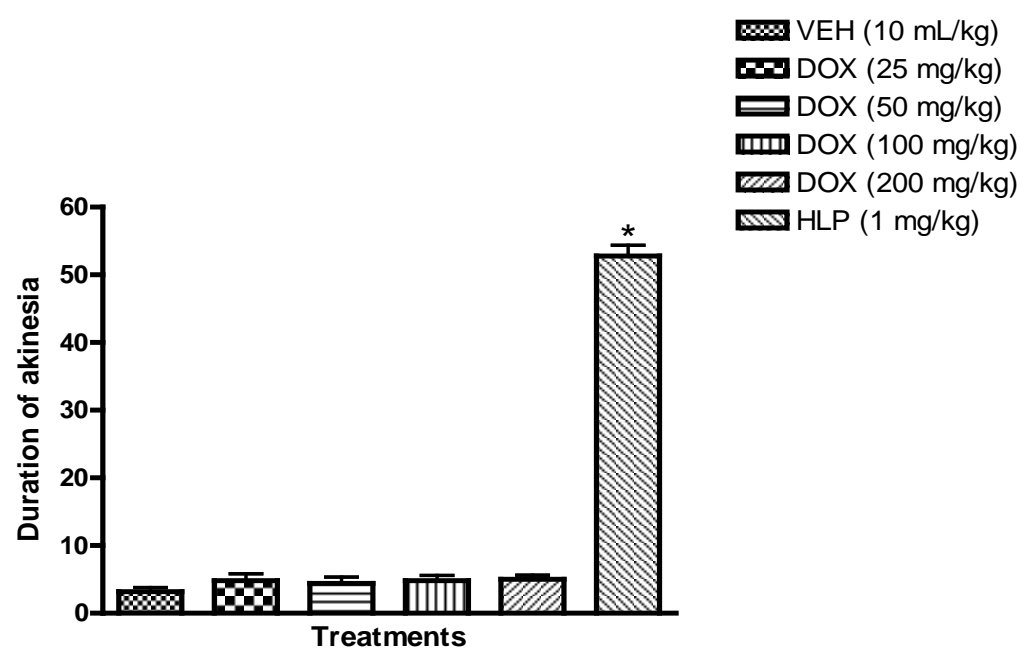

Figure 6. Effect of DOX on catalepsy test.

10 days significantly $(P<0.05)$ increased locomotion (hyperlocomotion) in the OFT compared to vehicle group, as indexed by the increase in the number of line crossings (Figure 7). Increased locomotion induced by ketamine was significantly $(P<0.05)$ prevented by DOX (100 and $200 \mathrm{mg} / \mathrm{kg}$, p.o./day) in a dose dependent manner following treatment for 10 days $[F(6,28)=31.67, P<0.0001]$; however, treatment with DOX ( 25 and $50 \mathrm{mg} / \mathrm{kg}$, p.o./day) failed to antagonize ketamine-induced hyperlocomotion. Furthermore, pretreatment with risperidone prior to ketamine treatment once daily for 10 days significantly reduced hyperlocomotion by ketamine (Figure 7).

\subsubsection{Effect of DOX on Ketamine-Induced Alteration in Working Memory}

The effect of DOX on ketamine-induced alteration in working memory as an index of 
cognitive impairment was assessed based on the sequence of arm entry and number of arm entries in the YMT (Figure 8). Sub-chronic ketamine (100 mg/kg, i.p./day) treatment for 10 days significantly $(P<0.05)$ decreased percentage alternations in YMT compared to vehicle-treated group. The administration of risperidone protected the animals against the cognitive deficits induced by ketamine. Also, pretreatment with DOX (100 and $200 \mathrm{mg} / \mathrm{kg}$, p.o./day) in combination with ketamine for 10 days demonstrated significant $(P<0.05)$ prevention against the alteration in working memory by ketamine as shown by the increase in the percentage alternations in the $\operatorname{YMT}[F(6,28)=$ 9.798, $P<0.0001]$ compared to the ketamine treated group. However, treatment with
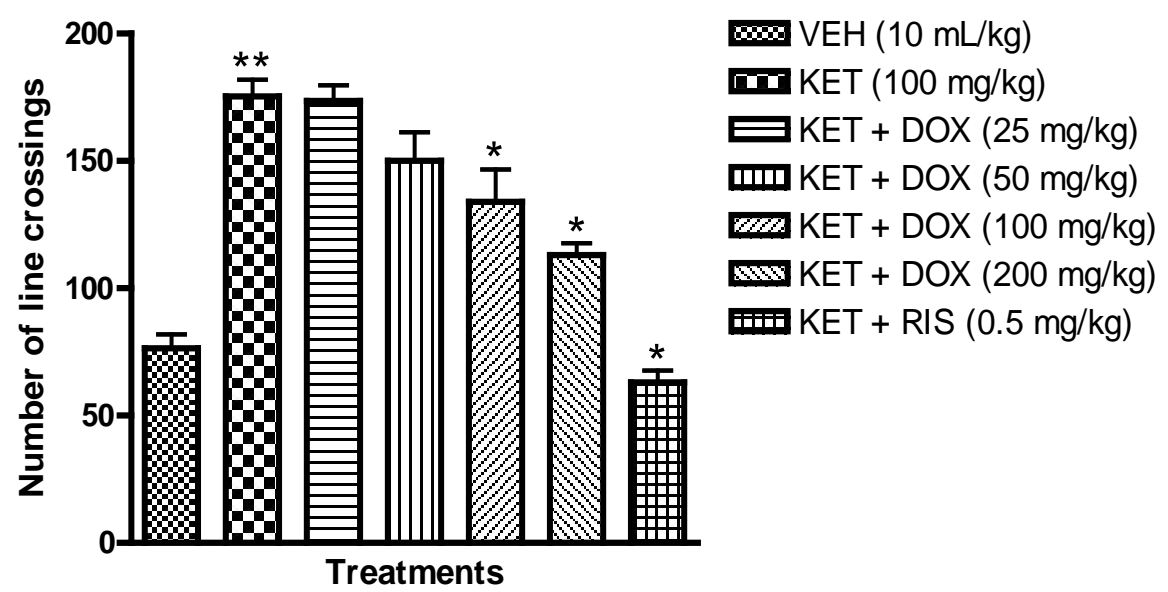

Figure 7. Effect of sub-chronic administration of DOX on ketamine-induced hyperlocomotion. Value represents the mean \pm S.E.M of 5 animals/group. ${ }^{\star *}$ Denotes $P<0.05$ compared with vehicle group. ${ }^{\star}$ Denotes $P<0.05$ compared with ketamine group (ANOVA followed by Newman-Keuls test). VEH $=$ Vehicle, KET $=$ Ketamine, RIS $=$ Risperidone, DOX = Doxycycline.
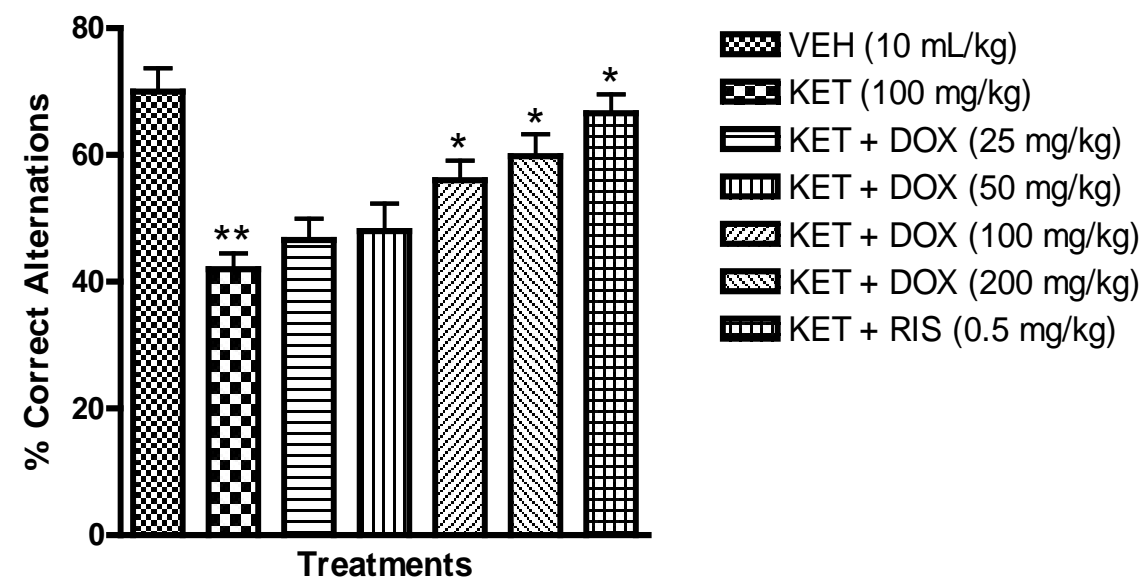

Figure 8. Effect of DOX on ketamine-induced alteration in working memory. Value represents the mean \pm S.E.M of 5 animals/group. ${ }^{\star *}$ Denotes $P<0.05$ compared with vehicle group. ${ }^{\star}$ Denotes $P<0.05$ as compared with ketamine group. (ANOVA followed by Newman-Keuls test). VEH $=$ Vehicle, $\mathrm{KET}=$ Ketamine, $\mathrm{RIS}=$ Risperidone, $\mathrm{DOX}=$ Doxycycline. 
lower dose of DOX (25 and $50 \mathrm{mg} / \mathrm{kg}$, p.o./day) failed to demonstrate significant ( $P>$ 0.05) effect against ketamine-induced alteration in working memory (Figure 8).

\subsubsection{Effect of DOX on Ketamine-Enhanced Immobility (Behavioral Despair) in Forced Swim Test in Mice}

Furthermore, the effect of sub-chronic pretreatment of DOX (25, 50, 100 and $200 \mathrm{mg} / \mathrm{kg}$, p.o./day) for 10 days against ketamine-induced enhancement of immobility as an index of behavioral despair (negative symptoms) was demonstrated as shown in Figure 9. Ketamine $(100 \mathrm{mg} / \mathrm{kg}$, i.p./day) administration for 10 days significantly $(P<0.05)$ enhanced the duration of immobility in the forced swim test (FST) compared to vehicle control group. Pretreatment with $\operatorname{DOX}(25,50,100$ and $200 \mathrm{mg} / \mathrm{kg}$, p.o./day) prior to ketamine administration significantly $(P<0.05)$ decreased immobility time in a dose dependent manner $[F(6,28)=23.66, P<0.0001]$ compared to ketamine treated group. Similarly, effect was also observed in the group pretreated with risperidone $(0.5 \mathrm{mg} / \mathrm{kg}$, p.o./day)prior to ketamine administration, as it also significantly $(P<0.05)$ prevented the increase in immobility time of the mice compared to ketamine treated group (Figure 9).

\subsubsection{Amelioration of Biomarkers of Oxidative Stress in Mice Brain}

The effect of DOX on the levels of antioxidant biomarkers of mice brains was done to assess for protection against oxidative stress following co-administration of DOX (25 $200 \mathrm{mg} / \mathrm{kg}$, p.o.) and ketamine (100 mg/kg, i.p.) for 10 days (Table 2). Ketamine administration significantly decreased SOD and CAT activities in the whole brain of mice compared with the vehicle-treated group (Table 2). Pretreatment with DOX (50, 100 and $200 \mathrm{mg} / \mathrm{kg}$, p.o./day) prior to the administration of ketamine significantly $(P<$ $0.05)$ increased SOD $[F(6,28)=44.81, P<0.0001]$ and CAT $[F(6,26)=39.29, P<$ $0.0001]$ activities compared to ketamine treated group. RIS, in turn, ameliorated the decrease in SOD and CAT activity by ketamine. Meanwhile, treatment with lower dose of DOX (25 mg/kg, p.o.) failed to significantly protect the animals against ketamine induced

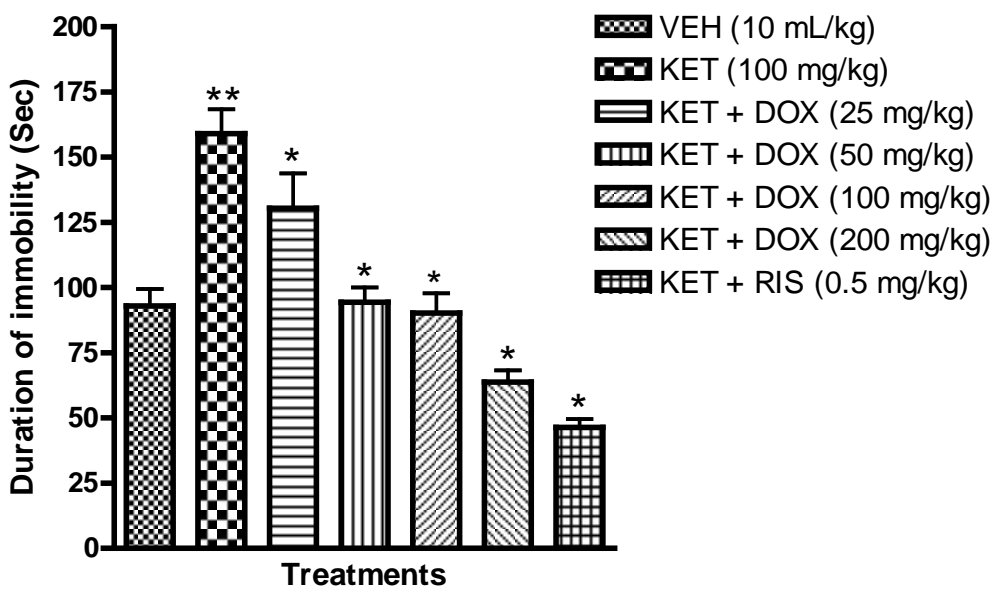

Figure 9. Effect of Sub-chronic administration of DOX on ketamine-enhanced immobility in forced swim test in mice. 
Table 2. Prevention of alterations of biomarkers of oxidative stress in mice whole brain subjected to sub-chronic ketamine treatment by doxycycline.

\begin{tabular}{|c|c|c|c|c|}
\hline Treatments & $\begin{array}{c}\text { SOD }(\text { Unit/mg } \\
\text { protein) }\end{array}$ & $\begin{array}{l}\text { CAT (Unit/mg } \\
\text { protein) }\end{array}$ & $\begin{array}{c}\text { GSH } \\
\text { (nmole/g tissue) }\end{array}$ & $\begin{array}{c}\text { MDA } \\
\text { (nmole/g tissue) }\end{array}$ \\
\hline VEH $(10 \mathrm{~mL} / \mathrm{kg})$ & $6.76 \pm 0.35$ & $4.64 \pm 0.22$ & $140.0 \pm 5.40$ & $16.64 \pm 0.78$ \\
\hline KET (100 mg/kg) & $2.34 \pm 0.27^{\star *}$ & $1.24 \pm 0.24^{\star *}$ & $60.4 \pm 5.51^{\star *}$ & $33.20 \pm 2.51^{\star *}$ \\
\hline DOX $(25 \mathrm{mg} / \mathrm{kg})+\mathrm{KET}$ & $3.70 \pm 0.20$ & $1.74 \pm 0.12$ & $106.8 \pm 6.05^{*}$ & $29.20 \pm 1.53$ \\
\hline $\mathrm{DOX}(50 \mathrm{mg} / \mathrm{kg})+\mathrm{KET}$ & $4.28 \pm 0.19^{*}$ & $3.84 \pm 0.22^{\star}$ & $146.2 \pm 10.07^{\star}$ & $10.42 \pm 1.23^{\star}$ \\
\hline $\mathrm{DOX}(100 \mathrm{mg} / \mathrm{kg})+\mathrm{KET}$ & $7.46 \pm 0.23^{\star}$ & $4.60 \pm 0.32^{*}$ & $178.8 \pm 6.95^{\star}$ & $11.78 \pm 0.85^{\star}$ \\
\hline $\mathrm{DOX}(200 \mathrm{mg} / \mathrm{kg})+\mathrm{KET}$ & $7.56 \pm 0.41^{\star}$ & $5.66 \pm 0.40^{*}$ & $173.6 \pm 7.39^{*}$ & $9.00 \pm 1.30^{*}$ \\
\hline RIS $(0.5 \mathrm{mg} / \mathrm{kg})+\mathrm{KET}$ & $6.58 \pm 0.39^{*}$ & $5.02 \pm 0.26^{*}$ & $159.6 \pm 7.69^{*}$ & $13.58 \pm 1.36^{*}$ \\
\hline
\end{tabular}

Value represents the mean \pm S.E.M of 5 animals/group. ${ }^{*}$ Denotes $P<0.05$ compared with vehicle group, ${ }^{\star}$ Denotes $P<$ 0.05 compared with KET treated group (ANOVA followed by Newman-Keuls test). VEH $=$ Vehicle, KET $=$ Ketamine, RIS $=$ Risperidone, DOX $=$ Doxycycline.

decrease in SOD and CAT enzyme activities compared to ketamine treated group. Furthermore, the administration of ketamine also significantly decreased the GSH concentration in the brain of the animals (Table 2) compared with the vehicle treated group. However, pretreatment with $\operatorname{DOX}(25,50,100$ and $200 \mathrm{mg} / \mathrm{kg}$, p.o.) and RIS (0.5 $\mathrm{mg} / \mathrm{kg}$, p.o.) significantly prevented $(P<0.05)$ the decrease in GSH concentration $[F(6$, 28) $=33.92, P<0.0001]$ compared to ketamine treated group.

Moreover, the pretreatment with DOX (50, 100 and $200 \mathrm{mg} / \mathrm{kg}$, p.o./day) but not with DOX (25 mg/kg, p.o.) prior to the administration of ketamine $(100 \mathrm{mg} / \mathrm{kg}$, i.p./ day) significantly $(P<0.05)$ protected the animals against ketamine induced lipid peroxidation as indexed by the decrease in malondialdehyde $(\mathrm{MDA})[F(6,28)=42.81, P$ $<0.0001$ ] levels in the whole brain of the animals (Table 2). Meanwhile, 10 days administration of ketamine alone significantly increased lipid peroxidation as the consequences of decrease in the endogenous antioxidants (SOD, CAT and GSH) compared to vehicle treated group (Table 2).

\section{Discussion}

Current evidences support oxidative and nitrosative stress, as well as inflammatory responses resulting from microglial hyperactivation as signaling mechanisms, outside the long believed dopamine hypothesis in the pathogenesis of schizophrenia [29] [30]. The results of this study revealed that single and repeated administration of doxycycline ameliorated schizophrenia-like behaviors and reduced the increased brain levels of biomarkers of oxidative stress induced by repeated administration of ketamine.

Neurobehavioral effects of DOX on novelty-induced rearing (NIR) in mice were assessed. Rearing is a vertical locomotor activity involving an animal standing on its hind limbs while raising up with its forearms in the air or placed on the wall of the cage [31]. It is an indication of an increase in exploratory behavior, which is a measure of central nervous system excitation [32]. It is important to note that biochemical data have 
shown that neurotransmitter like dopamine is implicated in central nervous system excitation [16]. Therefore, the decrease in NIR in this study by DOX is suggestive of possible interference with central dopaminergic neurotransmission and tranquilizing effect. Animal models using blockade of stereotypy behaviors, the degree of which are usually heightened when induced with apomorphine [18] or ketamine [20] is a valid tool for screening agents with suspected neurolepic activity. The stereotypic effects of apomorphine and ketamine have been shown to be mediated through the stimulation of dopamine receptors [33] and noncompetitive blockade of NMDA glutamate receptors [34], thereby indirectly decreasing the glutamate-dopamine pathway [33], respectively. Therefore, inhibition of these behavioral perturbations induced by apomorphine and ketamine herein by DOX suggests a neuroleptic activity. The observation from this study thus corroborates other studies that have demonstrated antipsychotic-like activity using inhibition of apomorphine- and ketamine-induced stereotypy in mice [17] [35].

The accentuation of locomotor activity has been majorly linked to the dopaminergic hyperactivation in the striatal areas of the brain [36]. Because the systemic administration of dopamine antagonists counteracts the hyperlocomotion induced by the administration of NMDA receptor antagonist [37], it is therefore; suggestive that dopamine neurotransmission is involved in the motor activating effects of ketamine-induced hyperlocomotion [16]. The inhibition of acute and sub-chronic ketamine-induced hyperlocomotion following single (200 mg/kg, p.o.) and repeated (100 and $200 \mathrm{mg} / \mathrm{kg}$, p.o.) administration of DOX respectively, further suggest that the drug possesses at least, some mild to moderate ability to ameliorate some form of positive symptoms of schizophrenia. The observation from this study on ketamine-hyperlocomotion is also in agreement with previous findings showing antipsychotic-like activity via antagonism of ketamine-induced hyperlocomotion [17] [20] [38]. Indeed, extrapyramidal symptoms are believed to develop from abnormal decreased dopamine activity in the striatum [20]. Therefore, preferential action of a novel neuroleptic agents against dopamine agonist-induced hyperactivity or stereotypy has been shown by previous studies, as an indicator of little or no extrapyramidal symptoms by novel antipsychotic agents [18] [21]. Hence, the test for extrapyramidal symptoms on catalepsy test in this study, demonstrated that DOX is devoid of cataleptic behavior which suggest the absence of extrapyramidal side effects.

Ketamine-induced enhancement of immobility in forced swim test (FST) following acute and sub-chronic administrations of DOX against ketamine, has been previously used as an animal model for behavioral despair in experimental mice; which is indicative of negative symptoms (anhedonia, social withdrawal) of schizophrenia [19] [39]. Acute DOX (50 - $200 \mathrm{mg} / \mathrm{kg}$ ) and sub-chronic DOX (25 - $200 \mathrm{mg} / \mathrm{kg})$ treatments demonstrated dose-dependent inhibition of ketamine enhanced immobility in FST comparable to risperidone. Of note, a recent study elsewhere demonstrated that risperidone reduced the enhanced duration of immobility by ketamine in experimental mice comparable to paroxetine, a selective serotonine reuptake inhibitor [19]. Thus, the effect of risperidone on the negative symptoms has been positively correlated to its 5-hydroxy- 
tryptaminergic (5-HT) $5 \mathrm{HT}_{2 \mathrm{~A}}$ receptor blocking action [20]. Besides, accumulating evidence shows that ketamine also bind to other allosteric sites in the brain, such as phencyclidine-binding site within the NMDA receptor channel complex [40] and dopamine- $\mathrm{D}_{2}$ receptor binding sites in the hippocampus [41]. However, the findings from Chindo et al. [19] suggest that ketamine-enhanced immobility in the FST might be mediated, at least in part, through $5-\mathrm{HT}_{2 \mathrm{~A}}$ receptors, since phencyclidine- and ketamine-enhanced immobility time are inhibited by $5-\mathrm{HT}_{2 \mathrm{~A}}$ receptor antagonists such as ritanserin, clozapine, risperidone and paroxetine, respectively [19] [20] [42]. Although, the neurotransmitter changes following ketmaine-enhanced immobility and the acute/ sub-chronic treatments with DOX respectively, in the present study have not yet been shown, the results of the present findings suggest that the mechanism of action of DOX against the negative symptoms of schizophrenia in ketamine-enhanced immobility may be in part, related to the modulation of 5-hydroxytryptaminergic system; meanwhile, the specific mechanism of action of this drug under this context is still under active investigation.

Also, in this study DOX (100 and $200 \mathrm{mg} / \mathrm{kg}$, p.o.) significantly prevented the cognitive impairment following repeated administration of ketamine for 10 days, as evaluated from the YMT. YMT has been used previously to measure the influence of suspected antipsychotic agents on cognitive functions [13] [17]. This study demonstrated that DOX prevented the cognitive impairment induced by ketamine; as indexed by the increase in the percentage correct alternations in YMT compared to ketamine treated group. In point of fact, the negative and cognitive symptoms of schizophrenia have been previously correlated to microglial hyperactivation and inflammatory involvements [30]. Taken together, the effects demonstrated by DOX may at least, in part, be mediated from its antioxidant and anti-inflammatory actions [43] [44].

Evidence derived supports oxidative stress in the pathophysiology of schizophrenia [45]. In fact, accumulating body of evidences has reportedly demonstrated increase in the concentrations of oxidative stress parameters after treatment with classical antipsychotics such as, haloperidol [7] [8] [15] [46]; and that treatments with antioxidants like vitamin E lowered the levels of reactive oxygen species (ROS) and protected the cells. So, it is suggested that novel antipsychotic compounds with antioxidants potential might be useful in the treatment of oxidative stress pathology associated with schizophrenia [7]. Indeed, besides stimulating the schizophrenic phenotypes, chronic ketamine treatment is also known to induce oxidative aberrations which correlates with those described in postmortem brains of individuals with schizophrenia [47]. Also, based on the construct, aetiologic and predictive validity with respect to both clinical phenomena and responsiveness to antipsychotic drugs [13] [16], it was thus, chosen for the present study to evaluate the possible anti-oxidative effects of DOX in the repeated administration of ketamine-induced oxidative alterations.

Therefore, the results from the biochemical assays in this study revealed that DOX (50 - $200 \mathrm{mg} / \mathrm{kg}$, p.o.) significantly decreased the biomarker of lipid peroxidation, as indexed by decreased MDA levels respectively, consequently to the increase in the an- 
tioxidant activity compared to the ketamine treated group. Moreover, DOX (25 - 200 $\mathrm{mg} / \mathrm{kg}$, p.o.) significantly increased GSH levels and activities of antioxidant enzymes including SOD and CAT in the whole brains of the experimental animals respectively. In the context of the present study, it might be inferred that the mechanism involved in the antipsychotic behavioral phenotypes of DOX majorly against the negative and cognitive symptoms of the experimental animals may be mediated, in part, through increase in antioxidant defense capacity and decrease in lipid peroxidation. Our study also showed that risperidone, an atypical antipsychotic agent, demonstrated an increase in the antioxidant defense mechanisms with a significant decrease in MDA levels compared to ketamine treated animals, which is in line with previous findings [13] [38] [48], and thus, further supports the role of oxidative stress in the pathophysiology of schizophrenia. In another study elsewhere, minocycline, a tetracycline congener of doxycycline demonstrated significant increase (preventive and reversal) in antioxidant defense systems, decrease in MDA and nitrite levels [13] [15]. In view of this, our findings confirmed that the schizophrenia-like behaviors induced by ketamine was accompanied by increased oxidative stress, as demonstrated by the decreased antioxidant defense systems and increased levels of MDA, respectively. Therefore, the ability of DOX to prevent ketamine-induced schizophrenia-like behaviors in the experimental animals may suggest an action involving the inhibition of biomarkers of oxidative stress in the mice brains.

From the glutamate-cycle, prolonged oxidative stress and immune alterations reduces the capacity of astrocytes to import glutamate, facilitating an increased extracellular glutamate levels [15] [30] [45]. Oxidative stress increased glutamate levels can inhibit cystine uptake by the cysteine/glutamate exchange system thereby causing intracellular GSH depletion, and consequently poor NMDA surface expression that results in NMDA hypofunctionality [34]; leading to decrease glutamate-dopamine modulations, that is, at least partly, mediated by decreased GSH signaling [49]. Moreover, Behrens et al. [45] and Sorce et al. [50] previously reported increase in the level of the pro-inflammatory cytokine, interleukine-6 (IL-6) and superoxide producing enzyme, nicotinamide adenine denucleotide phosphate oxidase-2 (Nox-2) in the brain of rodents following repeated administration of ketamine, respectively. Therefore, the increased GSH concentration observed in this study by doxycycline might be mediated through prevention of microglial oxidative burst and inflammatory response elements, thereby enhancing microglial internalization of cysteine intracellularly [51], and cysteine uptake by the cysteine/glutamate exchange system to increase GSH synthesis [52]. The increase in GSH in this study, suggests enhanced glutamate uptake by the astrocytes, possibly leading to increase in the surface expression of NMDA receptor and glutamate binding for the modulation of dopamine neurotransmission [50]. Therefore, the positive effects of DOX on ketamine-induced schizophrenia-like behavioral phenotypes, further point to mechanisms of action involving antioxidant activities, demonstrated herein and the inherent anti-inflammatory properties [12] [44]. Although, additional preclinical studies are necessary to ascertain the precise mechanisms of action of 
doxycycline against schizophrenia-like behaviors particularly against the negative and cognitive symptoms in experimental animals, the present findings suggest inhibition of biomarkers of oxidative stress in ketamine model of psychosis.

\section{Limitations and Further Studies}

Limitations of this study include the following: 1) lack of evidence of pro-inflammatory cytokines e.g., interleukin (IL)-6, IL-1 $\beta$ to evaluate the anti-inflammatory effect of doxycycline, 2) lack of neurotransmitters e.g., dopamine, glutamate, gamma-amino butyric acid (GABA) level determinations. Therefore, further studies will be focused on the determination of the above limitations presented herein, as well as other brain neurochemical and cellular alterations associated with schizophrenia.

\section{Conclusion}

Our studies showed that doxycycline ameliorated schizophrenia-like behaviors via mechanism related to inhibition of oxidative stress and did not produce extrapyramidal side effects in mice. Our data also suggest that doxycycline may be useful as an adjunctive neuroleptic drug for the treatment of schizophrenia-like behaviors particularly in patients with negative symptoms and cognitive deficits.

\section{Acknowledgements}

We thank all technical Staffs of the Department of Pharmacology and Therapeutics, Delta State University, Abraka for their assistance during the course of this study.

\section{Conflict of Interest Statement}

The authors declare that there are no conflicts of interest.

\section{References}

[1] Tandon, R., Nasrallah, H.A. and Keshavan, M.S. (2009) Schizophrenia, "Just the Facts" 4. Clinical Features and Conceptualization. Schizophrenia Research, 110, 1-23. https://doi.org/10.1016/j.schres.2009.03.005

[2] Picchioni, M. and Murray, M.M. (2007) Schizophrenia. British Medical Journal, 335, 91-95. https://doi.org/10.1136/bmj.39227.616447.BE

[3] Larson, M.K., Walker, E.F. and Compton, M. (2010) Early Signs, Diagnosis and Therapeutics of the Prodromal Phase of Schizophrenia and Related Psychotic Disorders. Expert Review of Neurotherapeutics, 10, 1347-1359. https://doi.org/10.1586/ern.10.93

[4] Pogarell, O., Koch, W., Karch, S., Dehning, S., Müller, N., Tatsch, K., Poepperl, G. and Möller, H.J. (2012) Dopaminergic Neurotransmission in Patients with Schizophrenia in Relation to Positive and Negative Symptoms. Pharmacopsychiatry, 45, 36-41. https://doi.org/10.1055/s-0032-1306313

[5] Meltzer, H. (2010) Antipsychotic Agents \& Lithium. In: Katzung, B.G., Masters, S.B. and Trevor, A.J., Eds., Basic \& Clinical Pharmacology, 12th Edition, McGraw-Hill Companies, New York, 501-513.

[6] Tandon, R., Nasrallah, H.A. and Keshavan, M.S. (2010) Schizophrenia, "Just the Facts" 5. 
Treatment and Prevention Past, Present, and Future. Schizophrenia Research, 122, 1-23. https://doi.org/10.1016/j.schres.2010.05.025

[7] Dokuyucu, R., Kokacya, H., Inanir, S., Copoglu, U.S. and Erbas, O. (2014) Antipsychoticlike Effect of Minocycline in a Rat Model. International Journal of Clinical and Experimental Medicine, 7, 3354-3361.

[8] Pazvantoglu, O., Selek, S. and Okay, I.T. (2009) Oxidative Mechanisms in Schizophrenia and Their Relationship with Illness Subtype and Symptom Profile. Psychiatry and Clinical Neuroscience, 63, 693-700. https://doi.org/10.1111/j.1440-1819.2009.02015.x

[9] Garrido-Mesa, N., Zarzuelo, A. and Galvez, J. (2013) Minocycline: Far beyond an Antibiotic. British Journal of Pharmacology, 169, 337-352. https://doi.org/10.1111/bph.12139

[10] Holmes, N.E. and Charles, P.G.P. (2009) Safety and Efficacy Review of Doxycycline. Clinical Medicine: Therapeutics, 1, 471-482.

[11] Leite, L.M., Carvalho, A.G., Ferreira, P.L., Pessoa, I.X., Gonçalves, D.O., Lopes, A.A., Góes, J.G., Alves, V.C., Leal, L.K., Brito, G.A. and Viana, G.S. (2011) Anti-Inflammatory Properties of Doxycycline and Minocycline in Experimental Models: An in Vivo and in Vitro Comparative Study. Inflammopharmacology, 19, 99-110. https://doi.org/10.1007/s10787-011-0077-5

[12] Mello, B.S, Monte, A.S., McIntyre, R.S., Soczynska, J.K., Custódio, C.S., Cordeiro, R.C., Chaves, J.H., Vasconcelos, S.M., Nobre, H.V., de Sousa, F.C.F., Hyphantis, T.N., Carvalho, A.F. and Macêdo, D.S. (2013) Effects of Doxycycline on Depressive-Like Behavior in Mice after Lipopolysaccharide (LPS) Administration. Journal of Psychiatry Research, 47, 15211529. https://doi.org/10.1016/j.jpsychires.2013.06.008

[13] Monte, A.S., de Souza, G.C., McIntyre, R.S., Soczynska, J.K., dos Santos, J.V., Cordeiro, C., Ribeiro, B.M.M., de Lucena, D.F., Mendes, S.M., de Sousa, V.F., Carvalho, A.F. and Macêdo, D.S. (2013) Prevention and Reversal of Ketamine-Induced Schizophrenia Related Behavior by Minocycline in Mice: Possible Involvement of Antioxidant and Nitrergic Pathway. Journal of Psychopharmacology, 27, 1032-1043. https://doi.org/10.1177/0269881113503506

[14] Chaudhry, I.B., Hallak, J., Husain, N., Minhas, F., Stirling, J., Richardson, P., Dursun, S., Dunn, G. and Deakin, B. (2012) Minocycline Benefits Negative Symptoms in Early Schizophrenia: A Randomised Double-Blind Placebo-Controlled Clinical Trial in Patients on Standard Treatment. Journal of Psychopharmacology, 26, 1185-1193. https://doi.org/10.1177/0269881112444941

[15] Wood, S.J., Yücel, M., Pantelis, C. and Berk, M. (2009) Neurobiology of Schizophrenia Spectrum Disorders: The Role of Oxidative Stress. Annals of the Academy of Medicine Singapore, 38, 396-401.

[16] Chatterjee, M., Rajkumar, V., Surajit, G. and Gautam, P. (2012) Neurochemical and Molecular Characterization of Ketamine-Induced Experimental Psychosis Model in Mice. Neuropharmacology, 63, 1161-1171. https://doi.org/10.1016/j.neuropharm.2012.05.041

[17] Ben-Azu, B., Aderibigbe, A.O., Adeoluwa, O.A. and Iwalewa, E.O. (2016) Ethanol Extracts of Terminalia ivorensis (Chev A.) Stem Bark Attenuates the Positive, Negative and Cognitive Symptoms of Psychosis in Experimental Animal Models. British Journal of Pharmaceutical Research, 12, 1-14. https://doi.org/10.9734/BJPR/2016/28629

[18] Bourin, M., Poisson, L. and Larousse, C. (1986) Piracetam Interaction with Neuroleptics in Psychopharmacological Tests. Neuropsychobiology, 19, 93-96.

[19] Chindo, B.A., Adzu, B., Tijani, A.Y. and Karniyus, S.G. (2012) Ketamine-Enhanced Immobility in Forced Swim Test: A Possible Animal Model for the Negative Symptoms of Schi- 
zophrenia. Progress in Neuro-Psychopharmacology and Biological Psychiatry, 38, 310-316. https://doi.org/10.1016/j.pnpbp.2012.04.018

[20] Chatterjee, M., Singh, S., Kumari, R., Verma, A.K. and Palit, G. (2012) Evaluation of the Antipsychotic Potential of Panax quinquefolium in Ketamine Induced Experimental Psychosis Model in Mice. Neurochemical Research, 37, 759-770.

https://doi.org/10.1007/s11064-011-0670-4

[21] Omogbiya, I.A., Umukoro, S., Aderibigbe, A.O. and Adewale, G.B. (2013) Jobelyn Pretreatment Ameliorates Symptoms of Psychosis in Experimental Models. Journal of Basic Clinical Physiology and Pharmacology, 24, 331-336. https://doi.org/10.1515/jbcpp-2012-0073

[22] Dall'igna, O.P., Fett, P. and Gomes, M.W. (2007) Caffeine and Adenosine $A_{2 a}$ Receptor Antagonists Prevent Beta-Amyloid (25-35)-Induced Cognitive Deficits in Mice. Experimental Neurology, 203, 241-245. https://doi.org/10.1016/j.expneurol.2006.08.008

[23] Misra, H.P. and Fridovich, I. (1972) The Role of Superoxide Anion in the Autooxidation of Epinephrine and a Simple Assay for Superoxide Dismutase. Journal of Biological Chemistry, 247, 3170-3175.

[24] Sinha, A.K. (1972) Colorimetric Assay of Catalase. Analytical Biochemistry, 47, 389-394. https://doi.org/10.1016/0003-2697(72)90132-7

[25] Jollow, D.J., Michell, J.R., Zampaglione, N. and Gillete, J.R. (1974) Bromobenzene-Induced Liver Necrosis. Protective Role of Glutathione an Evidence for 3,4-Bromobenzene Oxide as the Hepatotoxic Metabolite. Pharmacology, 11, 151-169. https://doi.org/10.1159/000136485

[26] Okhawa, H., Ohishi, N. and Yagi, K. (1979) Assay for Lipid Peroxides in Animal Tissues by Thiobarbituric Acid Reaction. Analytical Biochemistry, 95, 351-358. https://doi.org/10.1016/0003-2697(79)90738-3

[27] Gornall, A.G., Bardawill. C.J. and David, M.M. (1949) Determination of Serum Protein by Means of Biuret Reaction. Journal of Biological Chemistry, 177, 751-766.

[28] Sedlak, J. and Lindsay, R.H. (1968) Estimation of Total, Protein-Bound, and Nonprotein Sulfhydryl Groups in Tissue with Ellman's Reagent. Analytical Biochemistry, 25, 192-205. https://doi.org/10.1016/0003-2697(68)90092-4

[29] Lieberman, J.A., Javitch, J.A. and Moore, H. (2008) Cholinergic Agonists as Novel Treatments for Schizophrenia: The Promise of Rational Drug Development for Psychiatry. American Journal of Psychiatry, 165, 931-936. https://doi.org/10.1176/appi.ajp.2008.08050769

[30] Monji, A., Kato, T. and Kanba, S. (2009) Cytokines and Schizophrenia: Microglia Hypothesis of Schizophrenia. Psychiatry and Clinical Neurosciences, 63, 257-265.

https://doi.org/10.1111/j.1440-1819.2009.01945.x

[31] Onigbogi, O., Ajayi, A.A. and Ukponmwan, O.E. (2000) Mechanisms of Chloroquine-Induced Body Scratching Behavior in Rats: Evidence of Involvement of Endogenous Opioid Peptides. Pharmacology, Biochemistry and Behavior, 65, 333-337. https://doi.org/10.1016/S0091-3057(99)00221-X

[32] Aderibigbe, A.O., Iwalewa, O.E., Adesina, S.K. and Agboola, O.I. (2010) Studies of Behavioral and Neural Mechanism of Aridanin Isolated from Tetrapleura tetraptera in Mice. International Journal of Pharmacology, 6, 480-486.

[33] Geyer, M.A. and Moghaddam, B. (2002) Animal Models Relevant to Schizophrenia Disorders. Neuropsychopharmacology, 50, 690-701.

[34] Krystal, J.H., Karper, L.P., Seibyl, J.P., Freeman, G.K., Delaney, R., Bremner, J.D., Heniger, G.R., Bowers, M.B. and Charney, D.S. (1994) Subanaesthetic Effects of the Non Competi- 
tive NMDA Antagonist, Ketamine, in Humans: Psychotomimetic, Perceptual, Cognitive, and Neuroendocrine Responses. Archives of General Psychiatry, 51, 199-214.

https://doi.org/10.1001/archpsyc.1994.03950030035004

[35] Taïwe, G.S., Elisabeth, N.B., Emmanuel, T., Amadou, D., Fleur, C.O.M., Gwladys, T.N., Neteydji, S., Dabole, B., Desire, P., Dzeufietm D., Dimo, T. and De Waard, M. (2012) Antipsychotic and Sedative Effects of the Leaf Extract of Crassocephalum bauchiense (Hutch.) Milne-Redh (Asteraceae) in Rodents. Journal of Ethnopharmacology, 143, 213-220. https://doi.org/10.1016/j.jep.2012.06.026

[36] Irifune, M., Shimizu, T. and Nomoto, M. (1991) Ketamine-Induced Hyperlocomotion Associated with Alteration of Presynaptic Components of Dopamine Neurons in the Nucleus Accumbens of Mice. Pharmacology, Biochemistry and Behavior, 40, 399-407. https://doi.org/10.1016/0091-3057(91)90571-I

[37] Gimenez-Llort, L., Martinez, E. and Ferre, S. (1997) Different Effects of Dopamine Antagonists on Spontaneous and NMDA-Induced Motor Activity in Mice. Pharmacology, Biochemistry and Behavior, 56, 549-553. https://doi.org/10.1016/S0091-3057(96)00295-X

[38] Ben-Azu, B., Aderibigbe, A.O., Ajayi, A.M. and Iwalewa, E.O. (2016b) Neuroprotective Effects of the Ethanol Stem Bark Extracts of Terminalia ivorensis in Ketamine-Induced Schizophrenia-Like Behaviors and Oxidative Damage in Mice. Pharmaceutica Biology, 1-9. https://doi.org/10.1080/13880209.2016.1190382

[39] Noda, Y., Yamada, K., Furukawa, H. and Nabeshima, T. (1995) Enhancement of Immobility in a Forced Swimming Test by Subacute or Repeated Treatment with Phencyclidine: A New Model of Schizophrenia. British Journal of Pharmacology, 116, 2531-2537. https://doi.org/10.1111/j.1476-5381.1995.tb15106.x

[40] Anis, N.A., Berry, S.C., Burton, N.R. and Lodge, D. (1983) The Dissociative Anaesthetics, Ketamine and Phencyclidine, Selectively Reduce Excitation of Central Mammalian Neurones by $N$-Methyl-Aspartate. British Journal of Pharmacology, 79, 565-575. https://doi.org/10.1111/j.1476-5381.1983.tb11031.x

[41] Becker, A., Peters, B., Schroeder, H., Mann, T., Huether, G. and Grecksch, G. (2003) Ketamine-Induced Changes in Rat Behaviour: A Possible Animal Model of Schizophrenia. Progress in Neuro-Psychopharmacology and Biological Psychiatry, 27, 687-700. https://doi.org/10.1016/S0278-5846(03)00080-0

[42] Noda, Y., Yamada, K., Furukawa, H., Nabeshima, T. (1995) Enhancement of Immobility in a Forced Swimming Test by Subacute or Repeated Treatment with Phencyclidine: A New Model of Schizophrenia. British Journal of Pharmacology, 116, 2531-2537. https://doi.org/10.1111/j.1476-5381.1995.tb15106.x

[43] Berman, B., Perez, O.A. and Zell, D. (2007) Update on Rosacea and Anti-Inflammatory Dose of Doxycycline. Drugs of Today, 43, 27-34. https://doi.org/10.1358/dot.2007.43.1.1025697

[44] Cazalis, J., Bodet, C., Gagnon, G. and Grenier, D. (2008) Doxycycline Reduces Lipopolysaccharide-Induced Inflammatory Mediator Secretion in Macrophage and ex Vivo Human Whole Blood Models. Journal of Periodontology, 79, 1762-1768. https://doi.org/10.1902/jop.2008.080051

[45] Behrens, M.M. and Sejnowski, T.J. (2009) Does Schizophrenia Arise from Oxidative Dysregulation of Parvalbumin-Interneurons in the Developing Cortex? Neuropharmacology, 57, 193-200. https://doi.org/10.1016/j.neuropharm.2009.06.002

[46] Sagara, Y. (1998) Induction of Reactive Oxygen Species in Neurons by Haloperidol. Journal of Neurochemistry, 71, 1002-1012. https://doi.org/10.1046/j.1471-4159.1998.71031002.x 
[47] Keilhoff, G., Becker, A., Grecksch, G., Wolf, G. and Bernstein, H.G. (2004) Repeated Application of Ketamine to Rats Induces Changes in the Hippocampal Expression of Parvalbumin, Neuronal Nitric Oxide Synthase and cFOS Similar to Those Found in Human Schizophrenia. Neuroscience, 126, 591-598.

https://doi.org/10.1016/j.neuroscience.2004.03.039

[48] West, A.R. and Grace, A.A. (2000) Striatal Nitric Oxide Signaling Regulates the Neuronal Activity of Midbrain Dopamine Neurons in Vivo. Journal of Neurophysiology, 83, 17961808.

[49] Wood, S.J., Berger, G.E., Wellard, R.M., Proffitt, T.M., McConchie, M., Berk, M., McGorry, P.D. and Pantelis, C. (2009) Medial Temporal Lobe Glutathione Concentration in First Episode Psychosis: A 1H-MRS Investigation. Neurobiology of Disease, 33, 354-357. https://doi.org/10.1016/j.nbd.2008.11.018

[50] Sorce, S., Schiavone, S., Tucci, P., Colaianna, M., Jaquet, V., Cuomo, V., Dubois-Dauphin, M., Trabace, L. and Krause, K.H. (2010) The NADPH Oxidase $\mathrm{NOX}_{2}$ Controls Glutamate Release: A Novel Mechanism Involved in Psychosis-Like Ketamine Responses. Journal of Neuroscience, 30, 11317-11325. https://doi.org/10.1523/JNEUROSCI.1491-10.2010

[51] Bridges, R., Victoria, L., Doug, L. and David, A.B. (2012) Thinking outside the Cleft to Understand Synaptic Activity: Contribution of the Cystine-Glutamate Antiporter (System $\mathrm{x}_{\mathrm{c}}^{-}$) to Normal and Pathological Glutamatergic Signaling. Pharmacological Reviews, 64, 780802. https://doi.org/10.1124/pr.110.003889

[52] Ikonomidou, C. and Kaindl, A.M. (2011) Neuronal Death and Oxidative Stress in the Developing Brain. Antioxidants and Redox Signaling, 14, 1535-1550.

https://doi.org/10.1089/ars.2010.3581

Submit or recommend next manuscript to SCIRP and we will provide best service for you:

Accepting pre-submission inquiries through Email, Facebook, LinkedIn, Twitter, etc.

A wide selection of journals (inclusive of 9 subjects, more than 200 journals)

Providing 24-hour high-quality service

User-friendly online submission system

Fair and swift peer-review system

Efficient typesetting and proofreading procedure

Display of the result of downloads and visits, as well as the number of cited articles

Maximum dissemination of your research work

Submit your manuscript at: http://papersubmission.scirp.org/

Or contact jbbs@scirp.org 